\title{
EFEKTIVITAS MODEL LEARNING CYCLE 7E (LC 7E) BERBASIS PENDEKATAN KONSTRUKTIVISME
}

\author{
Oleh: Andi Musdalifa \& Taqwa \\ Program Studi Manajemen Pendidikan Islam \\ Institut Agama Islam Negeri (IAIN) Palopo
}

\begin{abstract}
Abstrak
Permasalahan pokok dalam penelitian ini yaitu (1). Bagaimana hasil belajar matematika siswa kelas VII MTs. Batusitanduk yang tidak diajar dengan model Learning Cycle 7E berbasis pendekatan konstruktivisme? (2). Bagaimana hasil belajar matematika siswa kelas VII MTs. Batusitanduk yang diajar dengan model Learning Cycle 7E berbasis pendekatan konstruktivisme? (3). Apakah model Learning Cycle 7E berbasis pendekatan konstruktivisme efektif meningkatkan hasil belajar matematika siswa kelas VII MTs. Batusitanduk?. Penelitian ini menggunakan desain eksperimen dengan true-experimental tipe pre test-post test control group design dengan populasi yaitu seluruh siswa kelas VII MTs. Batusitanduk tahun ajaran 2015/2016 yang berjumlah 115 siswa. Teknik pengambilan sampel yang digunakan yaitu cluster random sampling sehingga terpilih dua kelas yang menjadi sampel yaitu kelas VII A sebagai kelas kontrol dengan jumlah 29 siswa dan kelas VII B sebagai kelas eksperimen dengan jumlah 29 siswa. Teknik pengumpulan data yaitu dengan pemberian tes dan lembar observasi aktivitas siswa. Analisis data menggunakan statistik deskriptif dan statistik inferensial. Hasil penelitian diperoleh ratarata nilai siswa sebelum perlakuan untuk kelas eksperimen sebesar 65,66 dan untuk kelas kontrol sebesar 67,31. Dari hasil uji statistik z diperoleh $z_{\text {hitung }}=-1,51$ dengan taraf signifikan 5\% diperoleh $z_{\text {tabel }}=-1,86$, sehingga $-z_{\text {hitung }} \geq-z_{\text {tabel }}$ maka $H_{0}$ diterima, artinya tidak ada perbedaan yang signifikan antara kedua kelas. Rata-rata nilai siswa setelah perlakuan untuk kelas eksperimen sebesar 75,83 dan untuk kelas kontrol sebesar 70,86. Dari hasil uji statistik z diperoleh $z_{\text {hitung }}=3,80$ dengan taraf signifikan $5 \%$ diperoleh $z_{\text {tabel }}=1,86$. Sehingga $z_{\text {hitung }}>z_{\text {tabel }}$, maka $H_{0}$ ditolak dan $H_{1}$ diterima, artinya hasil belajar kelas eksperimen lebih baik dari hasil belajar kelas kontrol.
\end{abstract}

Kata Kunci: Efektivitas, Model Learning Cycle 7E, Pendekatan Konstruktivisme, Hasil Belajar Matematika.

\section{A. PENDAHULUAN}

Matematika sebagai salah satu ilmu dasar, mempunyai peranan dalam pengembangan ilmu pengetahuan dan teknologi. Oleh karena itu, matematika yang diajarkan di sekolah terdiri atas bagian-bagian yang dipilih guna mengembangkan 
kemampuan-kemampuan dan membentuk pribadi siswa yang berpadu pada perkembangan ilmu pengetahuan dan teknologi.

Dalam proses pendidikan di sekolah, matematika diberikan mulai dari pendidikan dasar. Hal ini disebabkan matematika digunakan secara luas dalam ilmu pengetahuan dan teknologi sehingga perlu berbagai upaya pembelajaran yang optimal agar siswa menerima materi pelajaran matematika dengan baik. Dalam pembelajaran matematika, guru berperan sebagai pemimpin sekaligus fasilitator belajar, sedangkan siswa berperan sebagai individu yang belajar (Agus N Cahyo, 2013: 239).

Dalam hal menuntut ilmu atau belajar, Allah Swt. berfirman dalam Q.S. Al-Alaq (96) : $1-5$.

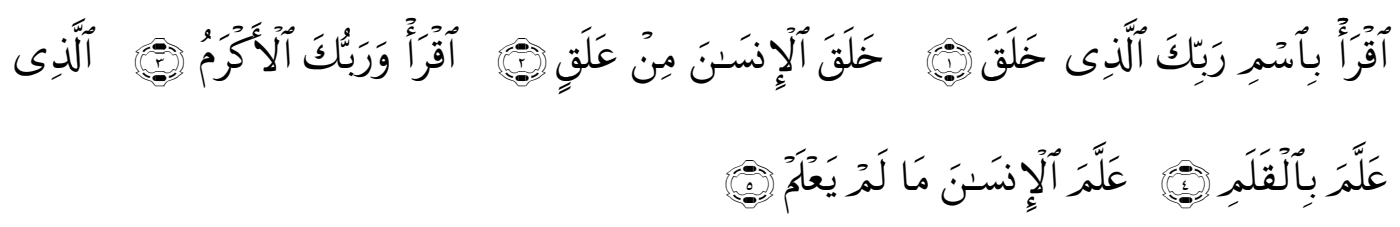

Terjemahnya:

"(1) Bacalah dengan (menyebut) nama Tuhanmu yang Menciptakan, (2) Dia telah menciptakan manusia dari segumpal darah. (3) Bacalah, dan Tuhanmulah yang Maha pemurah, (4) yang mengajar (manusia) dengan perantaraan kalam, (5) Dia mengajar kepada manusia apa yang tidak diketahuinya." (Departemen Agama RI, 2005: 598).

Ayat di atas menjelaskan tentang begitu pentingnya ilmu pendidikan, oleh karena itu pendidikan dari masa ke masa melakukan usaha perubahan dari baik menjadi lebih baik. Aktivitas belajar siswa sejak awal hingga sekarang terus terjadi inovasi dan kreasi, mulai dari kurikulum, pendekatan, metode serta saran dan teknik dalam pembelajaran.

Dari pengalaman penulis dan beberapa guru MTs. Batusitanduk selama ini dalam pembelajaran matematika masih banyak menggunakan metode konvensional, dimana proses pembelajaran matematika guru masih mendominasi dalam kegiatan belajar mengajar sehingga hasil belajar matematika siswa masih rendah.

Model pembelajaran Learning Cycle $7 E$ atau siklus belajar merupakan solusi atas permasalahan rendahnya hasil belajar matematika tersebut, karena model pembelajaran Learning Cycle $7 E$ merupakan suatu model pembelajaran yang berpusat pada siswa. Model ini terdiri dari tahap-tahap kegiatan yang diorganisasi sedemikian rupa sehingga siswa dapat menguasai kompetensi-kompetensi yang harus dicapai dalam pembelajaran dengan berperan aktif. Tahap-tahap tersebut adalah elicit (mendatangkan pengetahuan awal), engagement, (melibatkan), exploration (menyelidiki), explanation (menjelaskan), elaboration (menerapkan), evaluation (menilai), dan extend (memperluas) (Nur Kayati, 2015: 4-5). 
Model Learning Cycle $7 E$ menekankan siswa untuk dapat mengkonstruk sendiri pemikirannya sehingga pemahaman siswa akan konsep yang diajarkan diperoleh siswa dengan cara mengolah pikirannya sendiri. Selain itu, model ini memberikan aktivitasaktivitas sosial (misalnya diskusi atau tugas kerja siswa) sehingga merangsang siswa untuk mengkritisi dari apa yang dilihat, didengar, maupun yang dilakukan. Berdasarkan hal tersebut, Model Learning Cycle 7E dimungkinkan akan lebih efektif meningkatkan hasil belajar siswa.

Berdasarkan latar belakang masalah di atas maka peneliti tertarik untuk mengadakan penelitian tentang "Efektivitas Model Learning Cycle 7E (LC 7E) berbasis Pendekatan Konstruktivisme Terhadap Hasil Belajar Matematika Siswa Kelas VII MTs. Batusitanduk".

Dari latar belakang masalah tersebut, maka dapat dirumuskan permasalahan penelitian ini sebagai berikut:

1. Bagaimana hasil belajar matematika siswa kelas VII MTs. Batusitanduk yang tidak diajar dengan model Learning Cycle $7 E$ berbasis pendekatan konstruktivisme?

2. Bagaimana hasil belajar matematika siswa kelas VII MTs. Batusitanduk yang diajar dengan model Learning Cycle $7 E$ berbasis pendekatan konstruktivisme?

3. Apakah model Learning Cycle $7 E$ berbasis pendekatan konstruktivisme efektif meningkatkan hasil belajar matematika siswa kelas VII MTs. Batusitanduk?

\section{B. TINJAUAN PUSTAKA}

\section{Model Learning Cycle 7E (LC 7E)}

Learning Cycle adalah suatu model pembelajaran yang berpusat pada siswa. Learning Cycle merupakan rangkaian tahap-tahap kegiatan yang disusun sedemikian rupa sehingga siswa dapat menguasai sejumlah kompetensi yang harus dicapai dalam pembelajaran melalui peran aktivitas siswa.

Pada LC 7 fase (LC 7E) ini terdiri dari 7 tahap yaitu : elicit, engagement, exploration, explanation, elaboration, evaluation, dan extend (Lucki, 2014 : 2).

Secara operasional kegiatan guru dan siswa selama proses pembelajaran dapat dijabarkan sebagai berikut (Mitasari, 2013: 2-4).

a. Fase Elicit (Mendatangkan pengetahuan awal siswa)

Fase elicit yaitu fase untuk mengetahui sampai dimana pengetahuan siswa terhadap pembelajaran yang akan dipelajari dengan memberikan pertanyaan-pertanyaan yang merangsang pengetahuan awal siswa agar timbul respon dari pemikiran siswa serta menimbulkan rasa penasaran siswa tentang jawaban dari pertanyaan yang diajukan oleh guru. Fase ini dimulai dengan pertanyaan mendasar yang berhubunagn dengan pelajaran yang akan dipelajari dengan mengambil contoh yang mudah diketahui siswa seperti kejadian sehari- hari. Fase elicit bertujuan untuk melanjutkan, merangsang dan membuat 
siswa tertarik pada pelajaran yang akan dipelajari.

b. Fase Engagement (Melibatkan)

Fase engagement yaitu fase dimana siswa dan guru akan saling memberikan informasi dan pengalaman tentang pertanyaan- pertanyaan awal tadi, memberi tahu siswa tentang ide rencana pembelajaran sekaligus memotivasi siswa agar lebih termotivasi untuk mempelajari konsep dan memperhatikan guru dalam mengajar. Fase ini dapat dilakukan dengan diskusi, membaca, atau aktivitas lain yang digunakan untuk membuka pengetahuan siswa dan mengembangkan rasa keingintahuan siswa.

\section{c. Fase Exploration (Menyelidiki)}

Pada fase ini siswa memperoleh pengetahuan dari pengalaman langsung yang berhubungan dengan konsep yang dipelajari. Siswa diberi kesempatan untuk bekerja sama secara mandiri dalam kelompok-kelompok kecil. Pada fase ini siswa diberi kesempatan untuk mengamati gambar atau benda-benda yang ada disekitarnya, dan menafsirkan hasil, mengembangkan hipotesis serta mengatur temuan mereka. Guru merangkai pertanyaan, memberi masukan, dan menilai pemahaman siswa.

d. Fase Explanation (Menjelaskan)

Fase explanation, guru mendorong siswa untuk menjelaskan konsep dengan kalimat mereka sendiri, memberikan fakta dan klarifikasi terhadap penjelasannya, dan mendengarkan penjelasan siswa secara kritis.

e. Fase Elaboration (Menerapkan)

Pada fase ini siswa diberi kesempatan untuk menerapkan pengetahuannya pada situasi baru. Pada fase ini, guru memberikan permasalahan yang terkait dengan materi yang telah diajarkan untuk dipecahkan oleh siswa.

f. Fase Evaluation (Menilai)

Fase ini diisi dengan mengevaluasi seluruh pengalaman belajar siswa. Aspek yang dievaluasi pada fase ini adalah pengetahuan atau keterampilan, aplikasi konsep, dan perubahan proses berfikir siswa. Evaluasi dapat dilakukan secara tertulis pada akhir pembelajaran maupun lisan dalam bentuk pertanyaan selama belajar.

g. Fase Extend (Memperluas)

Pada fase extend guru membimbing siswa untuk menerapkan pengetahuan yang telah didapat pada konteks baru. Fase ini dapat dilakukan dengan cara mengaitkan materi yang telah dipelajari dengan materi selanjutnya.

Ketujuh tahapan tersebut adalah hal-hal yang harus dilakukan guru dan siswa untuk menerapkan Learning Cycle 7E pada pembelajaran di kelas. Guru dan siswa mempunyai peran masing-masing dalam setiap kegiatan pembelajaran yang dilakukan dengan menggunakan tahapan dari siklus belajar. Kegiatan pembelajaran lebih didominasi oleh peran siswa, sementara guru berperan sebagai fasilitator (Nur Kayati, 2015: 26). 


\section{Kelebihan dan kekurangan model Learning Cycle 7E}

Kelebihan dari model learning cycle 7E menurut Hardiansyah, (dalam Zulfiani, 2013, 25), antara lain:

a) Merangsang siswa untuk mengingat materi pelajaran yang telah mereka dapatkan sebelumnya.

b) Memberikan motivasi kepada siswa untuk menjadi lebih aktif dan menambah rasa keingintahuan siswa.

c) Melatih siswa belajar melakukan konsep melalui kegiatan eksperimen.

d) Melatih siswa untuk menyampaikan secara lisan konsep yang telah mereka pelajari.

e) Memberikan kesempatan kepada siswa untuk berpikir, mencari, menemukan, dan menjelaskan contoh penerapan konsep yang telah dipelajari.

f) Guru dan siswa menjalankan tahapan-tahapan pembelajaran yang saling mengisi satu sama lainnya.

g) Guru dapat menerapkan model ini dengan metode yang berbeda-beda.

Kelemahan model learning cycle 7E menurut Fajaroh ( 2010) adalah:

a) Efektifitas pembelajaran rendah jika guru kurang mengusai materi dan langkahlangkah pembelajaran.

b) Menuntut kesunggahan dan kreativitas guru dalam merancang dan melaksanakan proses pembelajaran.

c) Memerlukan waktu dan tenaga yang lebih banyak dalam menyusun rencana dan melaksanakan pembelajaran.

\section{Pendekatan pembelajaran konstruktivisme}

Pembelajaran konstruktivisme merupakan pembelajaran yang lebih menekankan pada proses dan kebebasan dalam menggali pengetahuan serta upaya dalam mengkonstruksi pengalaman (Nurdin, 2010: 153).

Salah satu perintis besar dalam teori konstruktivisme tentang pengetahuan adalah Jean Peaget. Jean Peaget lahir di Neuchâtel, Swiss, pada tanggal 9 Agustus 1896 (Anonim, 2010).

Konstruktivisme memandang bahwa pengetahuan itu berasal dari luar akan tetapi dikontruksi dari dalam diri seseorang. Karena itu pengetahuan terbentuk oleh objek yang menjadi bahan pengamatan dan kemampuan subjek untuk menginterprestasi objek tersebut. Lebih jauh Jean Piaget mengatakan hakikat pengetahuan adalah :

a) Pengetahuan bukanlah merupakan gambaran dunia nyata, akan tetapi merupakan kontriksi kenyataan melalui kegiatan, 
b) Subjek membentuk skema kognitif, kategori, konsep, dan struktur yang perlu untuk pengetahuan,

c) Pengetahuan dibentuk dalam struktur konsepsi seseorang, struktur konsepsi membentuk pengetahuan bila konsepsi itu berlaku dalam berhadaapan dengan pengalaman-pengalaman seseorang (Udin, 2012: 168-169).

\section{Hasil belajar matematika}

Hasil belajar adalah perubahan perilaku yang relatif menetap dalam diri seseorang sebagai akibat dari interaksi seseorang dengan lingkungannya. Hasil belajar memiliki beberapa ranah atau kategori dan secara umum merujuk kepada aspek pengetahuan, sikap, dan keterampilan (Hamzah, 2007: 213).

Dalam pencapaiannya, seringkali hasil belajar antara siswa satu dengan yang lainnya tidaklah sama. Hal ini dapat terjadi karena hasil belajar dipengaruhi oleh beberapa faktor. Secara garis besar, faktor-faktor yang mempengaruhi hasil belajar yaitu :

a) Faktor intern, dapat diklasifikasikan menjadi tiga yaitu (a) faktor jasmaniah, (b) faktor psikologis, dan (c) faktor kelelahan. Faktor jasmaniah meliputi kesehatan dan cacat tubuh, sedangkan yang dapat dikategorikan sebagai faktor psikologis adalah intelegensi, perhatian, minat, bakat, motif, kematangan, dan kesiapan.

b) Faktor ekstern, dapat diklasifikasikan menjadi tiga yaitu (a) faktor keluarga, (b) faktor sekolah, dan (c) faktor masyarakat. Faktor keluarga antara lain suasana rumah, cara orang tua mendidik, dan pengertian orang tua, sedangkan yang termasuk faktor sekolah antara lain, metode mengajar, kurikulum, hubungan guru dan siswa, dan hubungan antar siswa (Slameto, 2013: 54).

\section{METODE PENELITIAN}

\section{Pendekatan dan Jenis Penelitian}

Penelitian ini menggunakan pendekatan pedagogik yang bermaksud menghubungkan teori-teori pendidikan dengan fakta yang ada yaitu kondisi mutu proses pembelajaran yang telah berlangsung selama ini. Jenis penelitian yang dilakukan adalah jenis penelitian true eksperimental (eksperimen yang sebenarnya). Dikatakan true eksperimental karena dalam desain ini, peneliti dapat mengontrol semua variabel yang mempengaruhi jalannya eksperimen. Ciri utama dari true eksperimental adalah bahwa, sampel yang digunakan untuk ekperimen maupun sebagai kelompok kontrol diambil secara random dari populasi tertentu. Jadi cirinya adalah adanya kelompok kontrol dan sampel dipilih secara random (Sugiyono, 2012: 112). 


\section{Lokasi Penelitian}

Penelitian ini dilaksanakan di MTs. Batusitanduk pada semester genap kelas VII Tahun Pelajaran 2015/2016 yang beralamat di Jalan Trans Sulawesi, Desa Bolong, Kecamatan Walenrang Utara, Kabupaten Luwu.

\section{Variabel dan Desain Penelitian}

Dalam penelitian ini terdapat dua variabel yang akan diamati yaitu variabel $X$ dan $Y$. Variabel $X$ adalah model Learning Cycle dan variabel $Y$ adalah hasil belajar. Adapun desain penelitian true eksperimental yang digunakan adalah Pre test-Post test Control Group Design, dimana terdapat dua kelompok yang dipilih secara random, kemudian diberi pre test untuk mengetahui keadaan awal adakah perbedaan antara kelompok eksperimen dan kelompok kontrol. Hasil pretest yang baik bila nilai kelompok eksperimen tidak berbeda secara signifikan (Sugiyono, 2012: 113).

\section{Populasi dan Sampel}

Populasi dalam penelitian ini adalah seluruh siswa kelas VII MTs. Batusitanduk yang terdiri dari 4 kelas dengan jumlah keseluruhan 115 siswa. Pengambilan sampel dilakukan dengan menggunakan Cluster Random Sampling (sampel acak kelompok), dengan unit samplingnya adalah kelas. Berdasarkan teknik sampling tersebut terpilih kelas $\mathrm{VII}_{\mathrm{A}}$ berjumlah 29 siswa sebagai kelas kontrol dan $\mathrm{VII}_{\mathrm{B}}$ berjumlah 29 siswa sebagai kelas eksperimen.

\section{Teknik Pengumpulan Data}

Adapun teknik pengumpulan data yang dilakukan dalam penelitian ini yaitu metode observasi untuk mengetahui kelancaran selama proses pembelajaran maka digunakan daftar cek (check list) dan metode tes untuk memperoleh data hasil belajar matematika siswa pada pokok bahasan tertentu.

\section{Teknik Pengolahan dan Analisi Data}

a) Analisis Uji Coba Unstrumen

Sebelum tes diberikan kepada siswa maka tes perlu divalidasi dan direalibilitas untuk mengetahui tingkat validitas dan realibilitasnya.

b) Analisis Data Hasil Penelitian

Data yang diperoleh dari hasil penelitian ini dianalisis dengan dua teknik analisis statistika, yaitu :

1) Statistik Deskriptif

Statistik deskriptif digunakan untuk mendeskripsikan karakteristik responden, untuk keperluan analisa digunakan nilai maksimum, nilai minimum, rentang, rata-rata, variansi dan standar deviasi untuk masing-masing kelompok.

2) Statistik Inferensial

Statistik inferensial ini digunakan untuk menguji hipotesis penelitian yaitu dengan menggunakan uji z. namun sebelum dilakukan pengujian uji z terlebih 
dahulu dilakukan pengujian hipotesis yaitu uji normalitas dan uji homogenitas varians dari data hasil belajar matematika siswa.

\section{HASIL ANALISIS DAN PEMBAHASAN}

Hasil penelitian ini dapat dilihat dalam Tabel 4.a sampai dengan Tabel 4.i berikut ini:

Hasil Uji Coba Instrumen Pre-Test

\begin{tabular}{|c|c|c|c|c|}
\hline \multicolumn{2}{|c|}{ Validitas } & \multicolumn{3}{|c|}{ Reabilitas } \\
\hline$r_{x y}$ & Keterangan & $r_{11}$ & $r_{\text {tabel }}$ & Ket. \\
\hline 0,67 & Valid & \multirow{5}{*}{0,488} & \multirow{5}{*}{0,361} & \multirow{5}{*}{ Reliable } \\
\hline 0,657 & Valid & & & \\
\hline 0,691 & Valid & & & \\
\hline 0,519 & Valid & & & \\
\hline 0,521 & Valid & & & \\
\hline \multicolumn{5}{|c|}{ Hasil Uji Coba Instrumen Post-Test } \\
\hline \multicolumn{2}{|c|}{ Validitas } & \multicolumn{3}{|c|}{ Reabilitas } \\
\hline $\boldsymbol{T}_{x y}$ & Keterangan & $r_{11}$ & $r_{\text {tabel }}$ & Ket. \\
\hline 0,636 & Valid & \multirow{5}{*}{0,776} & \multirow{5}{*}{0,361} & \multirow{5}{*}{ Reliable } \\
\hline 0,853 & Valid & & & \\
\hline 0,684 & Valid & & & \\
\hline 0,748 & Valid & & & \\
\hline 0,839 & Valid & & & \\
\hline
\end{tabular}

Berdasarkan hasil di atas, maka soal pre-test dan post-test yang terdiri dari 5 soal dinyatakan layak digunakan pada kelas eksperimen dan kelas kontrol.

Persentase Ketuntasan Hasil Pre-Test Kelas Kontrol

\begin{tabular}{|c|c|c|c|c|}
\hline No. & Interval Skor & Interpretasi & Frekuensi & Persentase (\%) \\
\hline 1. & $69<x \leq 100$ & Tuntas & 11 & $37,9 \%$ \\
\hline 2. & $\leq 69$ & Tidak Tuntas & 18 & $62,1 \%$ \\
\hline \multicolumn{2}{r|}{ Jumlah } & $\mathbf{2 9}$ & $\mathbf{1 0 0 \%}$ \\
\hline
\end{tabular}

Persentase Ketuntasan Hasil Pre-Test Kelas Eksperimen

\begin{tabular}{|c|c|c|c|c|}
\hline No. & Interval Skor & Interpretasi & Frekuensi & Persentase (\%) \\
\hline 1. & $69<x \leq 100$ & Tuntas & 7 & $24,1 \%$ \\
\hline 2. & $\leq 69$ & Tidak Tuntas & 22 & $75,9 \%$ \\
\hline \multicolumn{2}{|r|}{ Jumlah } & $\mathbf{2 9}$ & $100 \%$ \\
\hline
\end{tabular}

Berdasarkan hasil analisis di atas dapat disimpulkan bahwa kedua kelas yang diteliti yaitu, kelas eksperimen dan kelas kontrol memiliki tingkat hasil belajar yang sama. Karena tidak mencapai 65\% siswa yang mendapatkan skor minimal 70. 
Persentase Ketuntasan Hasil Post-Test Kelas Kontrol

\begin{tabular}{|c|c|c|c|c|}
\hline No. & Interval Skor & Interpretasi & Frekuensi & Persentase (\%) \\
\hline 1. & $69<x \leq 100$ & Tuntas & 21 & $72,4 \%$ \\
\hline 2. & $\leq 69$ & Tidak Tuntas & 8 & $27,6 \%$ \\
\hline \multicolumn{2}{|r|}{ Jumlah } & 29 & $100 \%$ \\
\hline
\end{tabular}

Persentase Ketuntasan Hasil Post-Test Kelas Eksperimen

\begin{tabular}{|c|c|c|c|c|}
\hline No. & Interval Skor & Interpretasi & Frekuensi & Persentase (\%) \\
\hline 1. & $69<x \leq 100$ & Tuntas & 25 & $86,2 \%$ \\
\hline 2. & $\leq 69$ & Tidak Tuntas & 4 & $13,8 \%$ \\
\hline \multicolumn{2}{|r|}{ Jumlah } & $\mathbf{2 9}$ & $100 \%$ \\
\hline
\end{tabular}

Berdasarkan hasil analisis di atas dapat disimpulkan bahwa kedua kelas yang diteliti yaitu, kelas eksperimen dan kelas kontrol memiliki tingkat hasil belajar yang berbeda walaupun pada kedua kelas telah mencapai $65 \%$ siswa yang mendapatkan skor minimal 70. Tapi kelas eskperimen lebih tinggi tingkat persentase ketuntasannya dibanding kelas eksperimen.

Rekapitulasi Hasil Observasi Aktivitas Siswa

\begin{tabular}{|c|c|c|c|c|c|c|c|}
\hline \multirow{3}{*}{ No. } & \multirow{3}{*}{ Observer ke } & \multirow{2}{*}{\multicolumn{4}{|c|}{$\begin{array}{c}\text { Rekapitulasi Persentase } \\
\text { Pertemuan Ke }\end{array}$}} & \multirow{3}{*}{ Total (\%) } & \multirow{3}{*}{ Rata-rata (\%) } \\
\hline & & & & & & & \\
\hline & & $\mathrm{I}$ & II & III & IV & & \\
\hline 1. & Observer 1 & 60,7 & 64,3 & 78,6 & 85,7 & 289,3 & 72,3 \\
\hline 2. & Observer 2 & 53,6 & 60,7 & 75 & 85,7 & 275 & 68,8 \\
\hline \multicolumn{2}{|r|}{ Total (\%) } & 114,3 & 125 & 153,6 & 171,4 & & \\
\hline \multicolumn{2}{|c|}{ Rata-rata (\%) } & 57,2 & 62,5 & 76,8 & 85,7 & & 70,5 \\
\hline
\end{tabular}

Berdasarkan tabel di atas diperoleh kesimpulan bahwa persentase aktivitas siswa dengan menggunakan model Learning Cycle $7 E$ adalah 70,5\%. Berdasarkan kriteria keberhasilan tindakan, aktivitas siswa ini tergolong kategori "Baik" dengan interval skor $61 \% \leq P \leq 80 \%$.

Uji Normalitas

\begin{tabular}{|c|c|c|}
\hline Kelas & $x_{\text {hitung }}^{2}$ & $x_{\text {tabel }}^{2}$ \\
\hline Pre-Test Kontrol & 4,86 & 9,49 \\
\hline Pre-Test Eksperimen & 5,65 & 9,49 \\
\hline Pre-Test Kontrol & 7,82 & 9,49 \\
\hline Post-test Eksperimen & 9,31 & 9,49 \\
\hline
\end{tabular}

Karena $x_{\text {hitung }}^{2}<x_{\text {tabel }}^{2}$ pada kelas eksperimen dan kelas kontrol maka dapat disimpulkan bahwa data berdistribusi normal. 
Uji Homogenitas

\begin{tabular}{|c|c|c|}
\hline Kelas & $F_{\text {hitung }}$ & $F_{\text {tabel }}$ \\
\hline kontrol dan eksperimen pre-test & 1,09 & 2,05 \\
\hline kontrol dan eksperimen post-test & 1,88 & 2,05 \\
\hline
\end{tabular}

Karena $F_{\text {hitung }} \leq F_{\text {tabel }}$, sehingga dapat dikatakan data siswa mempunyai varians yang homoge.

Adapun analisis kesamaan dua rata-rata pada tahap awal sebelum perlakuan didapatkan $S_{g a b}=5,176$ dan $Z_{\text {hitung }}=-1,51$ dengan $\alpha=0,05$ maka diperoleh $Z_{\text {tabel }}=-1,86$. Jika $-Z_{\text {hitung }} \geq-Z_{\text {tabel }}$ maka $H_{0}$ diterima. Sehingga dapat disimpulkan bahwa hasil belajar siswa sebelum perlakuan yaitu kelas eksperimen dan kelas kontrol adalah sama atau tidak ada perbedaan. Sedangkan analisis kesamaan ratarata pada tahap akhir setelah perlakuan didapatkan $S_{\text {gab }}=7,69$ dan $Z_{\text {hitung }}=3,80$ dengan $\alpha=0,05$ maka diperoleh $Z_{\text {tabel }}=1,86$. Jika $Z_{\text {hitung }}>Z_{\text {tabel }}$ maka $H_{0}$ ditolak dan $\mathrm{H}_{1}$ diterima. Sehingga dapat disimpulkan bahwa hasil post-test kelas eksperimen lebih baik dari hasil post-test kelas kontrol.

\section{E. KESIMPULAN}

Berdasarkan masalah-masalah yang telah dikemukakan dan dirumuskan sebelumnya maka hasil penelitian ini dapat disimpulkan sebagai berikut :

1. Hasil belajar matematika siswa yang tidak diajar dengan model Learning Cycle 7E berbasis pendekatan konstruktivisme pada pokok bahasan Himpunan setelah pemberian tes diperoleh rata-rata sebesar 70,86 , skor tertinggi 85 , skor terendah 60 , standar deviasi 6,41 dan varians 41,05.

2. Hasil belajar matematika siswa yang diajar dengan model Learning Cycle 7E berbasis pendekatan konstruktivisme pada pokok bahasan Himpunan setelah pemberian tes diperoleh rata-rata sebesar 75,83 , skor tertinggi 95 , skor terendah 60 , standar deviasi 8,79 dan varians 77,29.

3. Berdasarkan hasil analisis data akhir dapat disimpulkan bahwa hasil belajar matematika siswa yang diajar dengan model Learning Cycle $7 E$ berbasis pendekatan konstruktivisme pada pokok bahasan Himpunan lebih baik dari hasil belajar siswa yang tidak diajar dengan model Learning Cycle $7 E$ berbasis pendekatan konstruktivisme. Hal ini menunjukkan bahwa model Learning Cycle $7 E$ berbasis pendekatan konstruktivisme efektif untuk meningkatkan hasil belajar matematika siswa. 


\section{DAFTAR PUSTAKA}

Anonim, http://belajar psikologi. com/teori-kepribadian-dan-motivasi-jean-piaget/, (8 Agustus 2016).

Aziz, Zulfiani, penggunaan model pembelajaran Learning Cycle 7E untuk meningkatkan hasil belajar siswa SMP pada pokok bahasan usaha dan energi, http://lib.unnes.ac.id Ipdf, (9 Agustus 2016).

Cahyo, Agus N, Panduan Aplikasi Teori Belajar Mengajar, Cet. I ; Yogyakarta : DIVA Press, 2013.

Departemen Agama RI, Al Quran dan Terjemahnya, Bandung: Jumanatul-Ali Art, 2005.

Fajaroh dan Dasna, Pembelajaran Dengan Model Siklus Belajar (Learning Cycle), http://sahaka.multiply.com/journal/item/29/pembelajarandengan model_siklus belajar learning cycle, (5 september 2015).

Hamzah B. Uno, Model Pembelajaran, Ed. I, Cet. I; Jakarta: Bumi Aksara, 2007.

Kaso, Nurdin, Filsafat Pendidikan, Cet. III; Palopo: LPK-Press STAIN Palopo, 2010.

Kayati, Nur, Efektivitas Model Learning Cycle 7E Terhadap Hasil Belajar Akuntansi di SMK Negeri 1 Salatiga, http://lib.unnes.ac.id/.pdf , (8 Agustus 2016)

Lucki, Penerapan Model Learning Cycle $7 E$ untuk Meningkatkan Motivasi Belajar Fisika dan Hasil Belajar Siswa Kelas X-2 MAN 2 Malang Kota Batu, http://jurnalonline.um.ac.id/data/artikel/.pdf , (21 April 2016).

Sa'ud, Udin Syaefudin, Inovasi Pendidikan, Cet. V ; Bandung : ALFABETA, 2012.

Slameto, Belajar dan Faktor-Faktor yang Mempengaruhinya, Cet. III; Jakarta : Rineka Cipta, 2003.

Sugiyono, Metode Penelitian Pendidikan, Cet. XV; Bandung: ALFABETA, 2012.

Widyaningsih, Mitasari, Peningkatan Aktivitas Belajar Siswa Melalui Model Pembelajaran Learning Cycle 7E pada Mata Pelajaran IPA Kelas V SD Muhammadiyah 2 Kauman Surakarta Tahun Ajaran 2012/2013, http:/leprints.ums.ac.Id/ NASKAH PUBLIKASI. pdf, ( 9 Agustus 2016) 